\section{Methodology required to show clinical differences between benzodiazepines}

M. Ansseau, M.D.,

A. Doumont, M.D., and

St. Diricq, M.D.

Unité de Psychopharmacologie, Hôpital Universitaire de Bavière, Liège, Belgium

Paper read: 10th July 1983

Curr. Med. Res. Opin., (1984), 8, Suppl. 4, 108.

\title{
Summary
}

Clinical differences exist between the benzodiazepines but demonstration of such differences requires a more specialized methodology than that normally used in comparative trials. It is recommended that double-blind studies should be carried out in hospitalized patients with severe and chronic anxiety, selected according to precise criteria, and that the trials should be designed as crossover rather than as parallel group studies, with randomization of the stages and flexible dosage. A simple graphic method of representing the clinical profile of individual benzodiazepines is described and it is suggested that this could help clinicians adapt their prescribing to each patient's symptoms.

Key words: Benzodiazepine tranquillizers - clinical trials - neuroses, anxiety

\section{Introduction}

In a recent letter to all advertisers of benzodiazepine prescription therapy, the U.S. Food and Drug Administration precludes the use of "comparative claims not demonstrated by substantial clinical experience and/or the use of non-clinical data to imply clinical significance when such clinical significance has not been demonstrated". Indeed, it is essential to prove clinically that differences between benzodiazepines exist, but such a demonstration requires a specialized methodology.

\section{Comparative drug trials: general principles}

Many authors assume a therapeutic equivalence between all benzodiazepine compounds marketed if the following are taken into account: (i) the potency of the products (with equivalent doses easy to determine) and (ii) the pharmacokinetics of the drugs with their active metabolites and their plasma half-lives. In fact, the lack of demonstrated clinical differences proceeds from the methodology generally used in comparative drug studies. Most of the clinical trials comparing benzodiazepines have been performed in anxious out-patients, not selected with precise criteria and suffering from only a moderate level of anxiety. In these subjects, non-pharmacological factors which are impossible to control play an important role and patient compliance is problematical. Indeed, some patients will 
return to their former anxiolytics in case of relative inefficacy of the prescribed treatment.

In order to demonstrate a difference in anxiolytic activity between compounds it is essential that strictly controllable methods are used. For example, the study should be carried out in a hospital environment in order to reduce the number of non-pharmacological variables, to be sure that the treatment is really taken and to stop the patient having recourse to other psychotropic drugs unknown by the investigator. Secondly, patients should be selected using precise diagnostic criteria such as 'generalized anxiety disorder' or 'panic disorder' from Research Diagnostic Criteria or the American Psychiatric Association (DSM III). Thirdly, patients selected should be suffering from severe anxiety, e.g. with a minimum score of 25 on the Hamilton Anxiety Rating Scale, in order to reduce the unavoidable placebo effect and obtain a treatment response close to a dose-effect relationship. Patients should also be those with chronic anxiety, e.g. a minimum duration of 1 year, as shown by the regular use of high doses of anxiolytic drugs, in order that it may be assumed that their condition is stable and spontaneous improvement is improbable. Obviously, those patients suffering from severe and chronic anxiety represent only a small sub-group not representative of all anxious people for whom benzodiazepine therapy could be useful; indeed, most prescribing of benzodiazepines is for mildly anxious out-patients over short periods. This sub-group with the highest level of pathology, however, is particularly suitable for the demonstration that one benzodiazepine may be more effective than another in the relief of anxiety.

We have applied these general principles of methodology in a study of prazepam, a long half-life benzodiazepine. The trial, reported in detail elsewhere ${ }^{4}$ was a double-blind comparison of the anxiolytic efficacy of prazepam given in two different schedules: (i) $10 \mathrm{mg}$ in the morning and at noon then $20 \mathrm{mg}$ in the evening, or (ii) placebo in the morning and at noon and $40 \mathrm{mg}$ in the evening. The trial sample was composed of two groups of 10 in-patients suffering from 'generalized anxiety disorder', as defined by Research Diagnostic Criteria, with severe (minimum score of 25 on the Hamilton Anxiety Rating Scale) and chronic anxiety (at least 1-year duration). The duration of this study was 3 weeks preceded and followed by 1 week on placebo. Clinical evaluation was performed every week using the Hamilton Anxiety Rating Scale and a visual analogue scale of response completed by the patient both in the morning and in the afternoon. The results clearly showed that prazepam produced significant improvement in both treatment groups but that it was more effective, better tolerated and able to provide a steadier clinical improvement during the whole day when given in divided dosage rather than as a single evening dose (Figures 1 and 2).

Perhaps the most sensitive methodology to show clinical differences between benzodiazepine compounds is the crossover trial design in which the effects of different treatments are compared in the same subject during successive periods. Such trials are particularly suitable for the evaluation of anxiolytics, which improve rather than cure, so that after the first treatment, the patient is in a position to receive a second one. ${ }^{5}$ To avoid the influence of the sequence order of the different treatments, the order of the periods should always be randomized and a balance between the treatment and order ensured. 
Figure 1. Mean Hamilton Anxiety Rating Scale scores after the wash-out period, after 1, 2 and 3 weeks of treatment with $\mathbf{4 0}$ mg praxepam per day, in divided or single doses, and after the final week on placebo

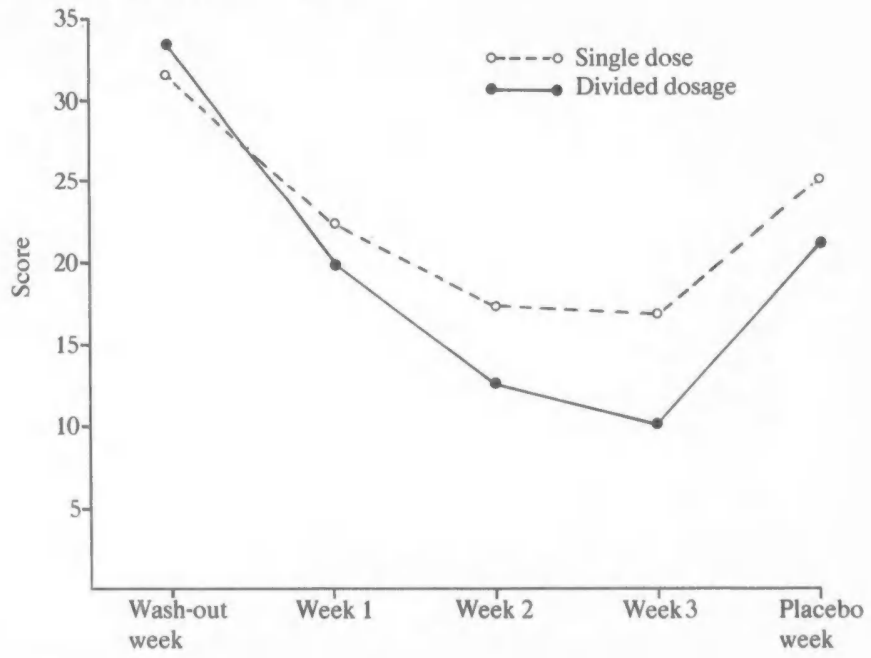

Figure 2. Mean visual analogue scale scores, morning and afternoon, after the wash-out period, after 1, 2 and 3 weeks of treatment with $\mathbf{4 0}$ mg prazepam per day, in divided or single doses, and after the final week on placebo

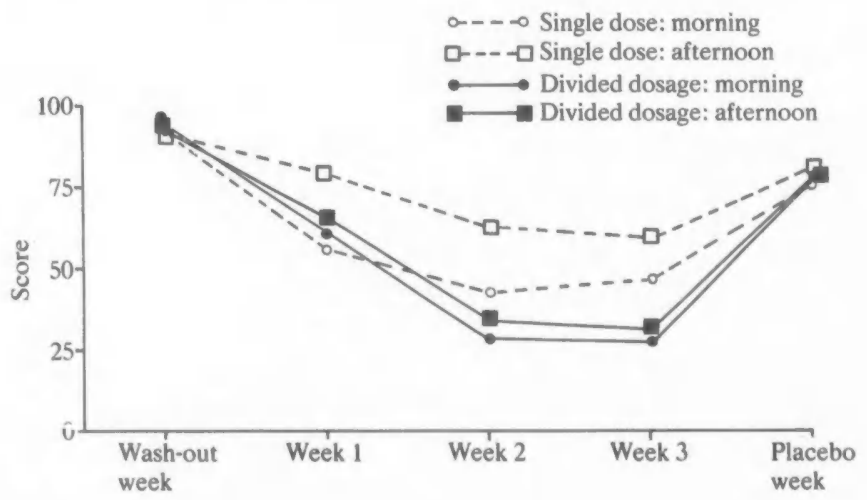

Crossover trial designs are substantially more sensitive than parallel group designs in evaluating the effects of benzodiazepines. For example, Kellner et al. ${ }^{6}$ reviewed the results of double-blind clinical studies comparing benzodiazepines and placebo. From 58 comparisons using independent parallel groups, 33 (57\%) 
showed a significant superiority of benzodiazepines. From 39 crossover comparisons, $31(79 \%)$ showed a significant difference in favour of the benzodiazepines. Even comparison studies with fewer than 20 patients were associated with a high proportion of positive results, whereas only independent group comparisons including more than 60 patients tended to yield a larger proportion of positive than negative results. Moreover, the crossover trial design permits using a shorter duration of treatment. Selection of patients is also often more rigorous and most of the non-drug effects are held constant. Also this method could allow the identification of individual responders and non-responders.

The crossover trial, however, is subject to criticism and some investigators are convinced that carry-over effects from one treatment to the next are likely to vitiate the results of these trials. But no evidence of such effects has been demonstrated for anxiolytic agents. ${ }^{7}$ On the contrary, the greater sensitivity in discriminating between active compound and placebo proves that carry-over effects are of little importance in crossover trials of benzodiazepines.

We used this methodology in a second $\operatorname{trial}^{3}$ to compare the anxiolytic efficacy of methylclonazepam, a potent new benzodiazepine, with that of a standard benzodiazepine (diazepam) and placebo. The trial was a double-blind crossover study in which the order of treatments was randomized according to a Latin square. Dosage was flexible. At the end of the trial period, 11 of the 18 patients studied chose methylclonazepam as the best form of treatment compared with only 1 patient who chose the standard benzodiazepine. None chose placebo treatment. The other 6 patients preferred both active treatments over placebo but did not discriminate between them. These results indicate a statistically significant $(\mathrm{p}<0.001$ ) superiority of methylclonazepam over the standard benzodiazepine and illustrate how the crossover design study carried out in only a small number of patients can yield more positive information than trials on large parallel groups.

\section{Clinical drug profiles: a graphic representation of comparative activity}

Given that clinical differences exist between benzodiazepine compounds it should be possible to choose the most appropriate drug for a particular patient's symptoms based on a comparison of the clinical effects of the different benzodiazepines available. In order to inform the general practitioner about the clinical properties of the various drugs, we proposed a simple graphic representation of the activity profile of each based on five parameters, namely, effect on psychic anxiety, effect on somatic anxiety, sedative/hypnotic effect, effect on muscle relaxation, and anti-epileptic effect, compared with that of a reference drug considered to have the greatest activity in one of the parameters. Comparisons, therefore, were made against diazepam (10 mg), lorazepam (2.5 mg), flunitrazepam (4 mg), diazepam $(10 \mathrm{mg})$ and clonazepam $(2 \mathrm{mg})$, respectively, for the individual parameters. It was arbitrarily decided to choose the highest dosage form available on the Belgian market of each benzodiazepine tested, although it is evident clinically that activity depends on the dosage used.

The methodology used was a single-blind comparison of each compound with 
Figure 3. Comparative clinical profiles after single doses of different benzodiazepines

$0=$ No effect
$1=$ Very weak effect
$2=$ Weak effect
$3=$ Moderate effect
$4=$ Potent effect
$5=$ Very potent effect

Chlordiazepoxide (25 $\mathrm{mg}$ )

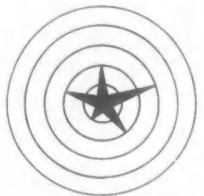

Nitrazepam (5 mg)

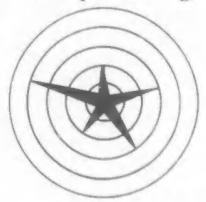

Lorazepam $(2.5 \mathrm{mg})$

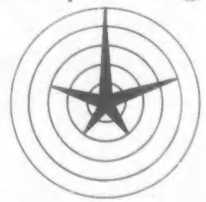

Flunitrazepam (4 mg)

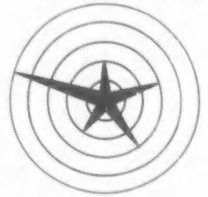

Clobazam (10 mg)

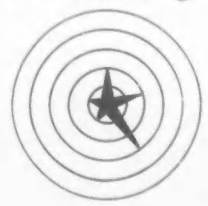

Somatic anxiety

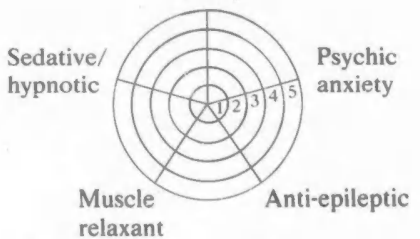

relaxant

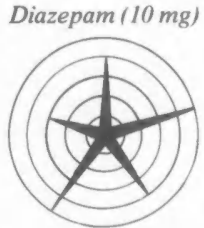

Medazepam (10 mg)

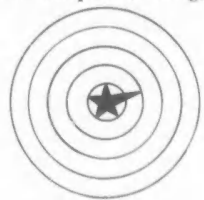

Bromazepam (12 mg)

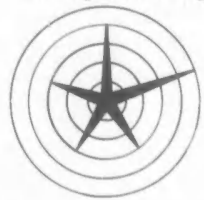

Temazepam (10 mg)

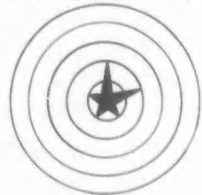

Triazolam (I mg)

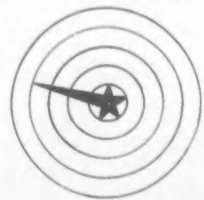

Oxazepam (1.5 mg)

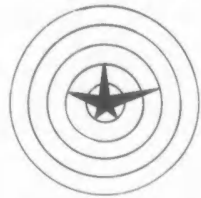

Clorazepate (10 mg)

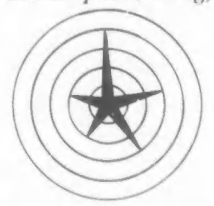

Clonazepam (2 mg)

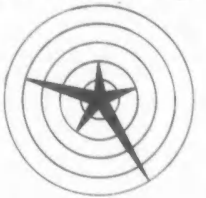

Camazepam (20 mg)

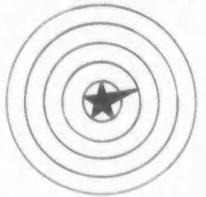

Prazepam (10 mg)

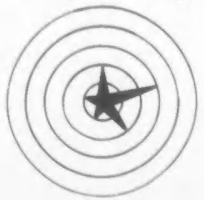


the reference benzodiazepine. On several different days anxious in-patients had a basal evaluation of their condition, using items derived from a modified Hamilton Anxiety Rating Scale, at 09.00 hours. They then received a single dose of the benzodiazepine being tested and were reassessed 2 hours later. The clinical results achieved with the reference drug were arbitrarily supposed to be maximal and the results with other compounds were rated by comparison according to the following definition: $0=$ no effect, $1=$ very weak effect, $2=$ weak effect, $3=$ moderate effect, $4=$ potent effect and $5=$ very potent effect. The mean scores, rounded off to the next number, have been used for the graphic representation of the results obtained for the various benzodiazepines available in Belgium (Figure 3).

Of necessity, this is a simplified comparative representation but it is hoped that presentation of data in such a way may assist the general practitioner in morc rational and better prescribing of benzodiazepines for his patients.

\section{Acknowledgements}

We would like to thank Mrs. Ch. Gayetot and Dr. J. Parcels, Statesboro, U.S.A., for their help in the preparation of this paper.

\section{References}

1. Ansseau, M., (1982). Les benzodiazépines: de la pharmacologie à la clinique, une approche pratique. Ars Med. 37, 241-257.

2. Anseeau, M., and Diricq, St., (1979). Les benzodiazépines. Upjohn Med. Monographs, 1 (10), 1-38.

3. Ansseau, M., Doumont, A., and Thiry, D., (1983). Princeps study of methylclonazepam in anxious disorders. Paper presented at the VII World Congress of Psychiatry. July 1983, Vienna. 4. Ansseau, M., Doumont, A., Von Frenckell, R., and Collard, J., (1983). Lack of direct relationship between plasma pharmacokinetics and clinical activity of benzodiazepines. A study performed with prazepam according to two different dosage schedules. Paper presented at the VII World Congress of Psychiatry. July 1983, Vienna.

5. Hills, M., and Armitage, P., (1979). The two-period cross-over clinical trial. Br. J. Clin. Pharmacol., 8, 7-20.

6. Kellner, R., Uhlenhuth, E. H., and Glass, R. M., (1978). Clinical evaluation of anti-anxiety agents: subject-own-control designs. In: "Psychopharmacology. A Generation of Progress", pp. 1391-1400. Eds.: M. A. Lipton, A. DiMascio and K. F. Killam. Raven Press, New York.

7. Raymond, M. J., Lucas, C. J., Beesley, M. L., O'Connell, B. A., and Roberts, J. A. F., (1957). A trial of five tranquillizing groups in psychoneurosis. Br. Med. J., 2, 63-66.

\section{Résumé}

Des différences cliniques existent entre les benzodiazépines, mais la démonstration de telles différences nécessite une méthodologie plus specialisée que celle normalement utilisée au cours des expérimentations cliniques comparatives. Il est recommandé que des études en double-aveugle soient pratiquées chez des patients hospitalisés présentant une anxiété sévère et chroniqus, sélectionnés en fonction de critères précis, et que les experimentations soient conçues sous forme de cross-over plutôt qu'en utilisant des groupes parallèles, avec une randomisation des stades et une posologie flexible. Une méthode graphique simple pour représenter le profil clinique des différentes benzodiazépines est décrite et il est suggéré que celle-ci pourrait aider les cliniciens à adapter leur prescription aux symptômes de chaque patient. 


\section{Zusammenfassung}

Es bestehen klinische Unterschiede zwischen den Benzodiazepinen aber die Darlegung solcher Unterschiede erfordert grössere spezialisierte Methoden als die üblichen angewandten Methoden in vergleichenden klinischen Prüfungen. Es ist daher empfehlenswert, dass doppel-blinde Studien im Krankenhaus durchgeführt werden und dass die Patienten auf grund schweren und chronischen Angstsyndromen ausgewählt werden gemäss genauer Kriterien und dass die klinischen Prüfungen als überkreuzende und nicht in parallen Gruppen geplant werden sollten mit periodischen Stichproben und anpassungsfähigen Dosierungen. Eine einfache graphische Methode zur Darstellung des klinischen Profils der einzelnen Benzodiazepinen ist beschrieben und es wird empfohlen, dass diese Darstellung den Ärzten hilft sich in ihren Rezepten den Symptomen jedes Patienten anzupassen.

\section{Resumen}

Existen diferencias clínicas entre las benzodiacepinas, pero la demostración de tales diferencias exige una metodología más especializada que la que suele emplearse habitualmente en las pruebas comparativas. Se recomienda realizar estudios doble ciegos entre pacientes hospitalizados afectos de ansiedad crónica y grave, seleccionados según criterios precisos, y que dichos estudios sean de tipo cruzado más que de grupos paralelos, con distribución aleatoria de las etapas y una posología flexible. Se describe un sencillo método gráfico de representar el perfil clínico de las distintas benzodiacepinas, y se propugna que éste pudiera ayudar a los clínicos a adaptar sus prescripciones a los sintomas de cada paciente. 